\title{
Associations between the general condition of culled dairy cows and selling price at Ontario auction markets
}

\author{
Allison K. G. Moorman, ${ }^{*} \dagger$ Todd F. Duffield, ${ }^{*} \dagger$ M. Ann Godkin, $\ddagger$ David F. Kelton, ${ }^{*} \dagger$ Jeffrey Rau, ${ }^{*}$ \\ and Derek B. Haley* ${ }^{1}$ \\ *Department of Population Medicine, University of Guelph, Guelph, ON, N1G 2W1, Canada \\ †Campbell Centre for the Study of Animal Welfare, University of Guelph, Guelph, ON, N1G 2W1, Canada \\ ‡Ontario Ministry of Agriculture, Food and Rural Affairs, Elora, ON, NOB 150, Canada
}

\section{ABSTRACT}

Dairy cows are culled from the herd for a variety of reasons, the most common being fertility problems, low milk production, or udder problems. Disease and injury can contribute to the decision to cull either directly, or indirectly, by causing fertility or production problems, leading to culling. Disease or injury may also affect the cow's ability to handle the stress of transportation and may increase the risk for reduced welfare. The purpose of this study was to determine the general condition of culled dairy cows sold at Ontario auction markets, to quantify the frequency of culled cows in poor condition sold at these auctions, and to determine how this relates to the sale price of the cow. Data were collected on 4,460 culled dairy cows, sold at 3 Ontario auction markets, over a continuous 16-wk study period. Observers assessed the general condition of dairy cows entering the sales ring by recording each individual cow's hock injury score, body condition score (BCS), gait score, and tail score, in accordance with 2017 Canadian proAction Animal Care guidelines. Each cow's body weight, breed, and sale price were also recorded. Results showed that $27.2 \%$ of culled cows scored had unacceptable hock injuries, $40.5 \%$ had a BCS $\leq 2,72.7 \%$ had an abnormal gait, and $12.5 \%$ had docked tails. Culled cows with a BCS $\leq 2$ sold for $\$ 0.20$ less $/ \mathrm{kg}$ compared with those with a BCS $>2$, which equated to an overall average loss of $\$ 117$ per cow. Cows with an abnormal gait sold for $\$ 0.05$ less $/ \mathrm{kg}$ compared with culled cows with a normal gait, which equated to an overall average loss of $\$ 32.45$ per cow. There was no difference in the sale price depending on hock injury score or the presence or absence of a full tail. The main issues identified in this study were the high prevalence of low body condition and abnormal gait, indicating that the welfare of these cows may be at risk. Additionally, cows with low BCS

Received January 30, 2018.

Accepted July 14, 2018.

${ }^{1}$ Corresponding author: dhaley@uoguelph.ca or abnormal gait sold for a lower price compared with cows that were in good condition, leading to reduced potential profit for the producer.

Key words: culled cow, cattle transportation, auction market

\section{INTRODUCTION}

The process surrounding the decision to cull, or to remove a cow from the herd, is quite complex in terms of overall farm production but also cow welfare (Langford and Scott, 2012). Culling is a routine practice with the annual culling rate, or the rate at which cows leave the herd, being above $30 \%$ of the herd in the United States (Hadley et al., 2006; De Vries et al., 2010; NFAHW, 2017). Most commonly in North America, culled cows are sent to slaughter; they are transported to an auction market, bought by abattoir representatives, and then further transported to the abattoir to enter the food chain (Fetrow et al., 2006). The most common risk factors for culling are reproductive problems, low milk production, or udder problems (Milian-Suazo et al., 1989; Beaudeau et al., 1993; Bascom and Young, 1998; Chiumia et al., 2013). The presence of injury or other diseases, however, can both directly and indirectly increase the risk of culling for dairy cows, as cows may be culled specifically because of that condition, or because its presence negatively affects the cow's performance (Dohoo and Martin, 1984; Grohn et al., 1998; RajalaSchultz and Grohn, 1999a,b). In fact, Beaudeau et al. (1993) found that at least half of all culling decisions are associated with health problems. This finding can be further supported by studies that have found an association between lameness and reproductive problems, mastitis, and reduced milk production (Barkema et al., 1994; Booth et al., 2004), as well as reproduction and production problems (Martin et al., 1982; Dohoo and Martin, 1984; Rajala-Schultz and Grohn, 1999b). However, the complex reasons for culling are typically not observed in farm records as dairy producers commonly record only one primary reason for culling, and 
therefore the full influence of all culling factors is not captured (Bascom and Young, 1998).

As stated in both the Codes of Practice for the Care and Handling of Dairy Cattle (National Farm Animal Care Council, 2009) and the Health of Animals Regulations Part XII (Canadian Food Inspection Agency, 2016), producers should transport only healthy animals. It follows that animals that are unable to cope with the stress of transport due to disease, injury, or any other factors which may affect their welfare, should not be transported. As mentioned above, a cow may be culled and subsequently transported to an auction market with an injury or disease that affects their performance (Milian-Suazo et al., 1989; Bascom and Young, 1998; Chiumia et al., 2013), but that disease or injury could also put their welfare at risk during transport (Langford and Scott, 2012). Additionally, the disease or injury may be exacerbated by transport; however, currently no data are available to determine to what extent. To the best of our knowledge, no current published reports are available on the general condition of cows transported to, and sold at, Ontario auction markets. Therefore, it is difficult to quantify if, and how frequently, compromised animals are transported. Furthermore, no research has been published on the potential effect of culled cow condition on market price.

The objective of this study was to assess the general physical condition of culled dairy cows sold at Ontario auction markets and to determine if a relationship was present between their condition and the sale price. Assessment of each culled cow was made in accordance with the Dairy Farmers of Canada proAction Animal Care guidelines (DFC-PLC, 2017). ProAction is a Canadian audit that uses animal-based measures for scoring the health and welfare of farmed dairy cattle and is the first animal care audit to be nationally implemented within Canada. We hypothesized that culled cows sold at auction in suboptimal condition, as determined by using proAction Animal Care animal-based evaluation methods (DFC-PLC, 2017), would sell for less compared with cows that were in good condition.

\section{MATERIALS AND METHODS}

\section{Data Collection}

Culled dairy cows, sold at auction, were visually observed and evaluated during weekly sales at licensed Ontario livestock auction markets. The livestock auction markets $(\mathrm{n}=3)$ were visited from May to August 2017, inclusive. This study was designed as a crosssectional observational study. Observers had no influence on the care and handling of the cattle being sold.
Through the use of Beef Farmers of Ontario weekly auction market reports, we determined that 28 licensed auction markets in Ontario were selling over 2,000 culled cows a week. Based on ring announcements at sales, it was determined that Ontario receives cattle from other provinces outside of Ontario. Additionally, Ontario is also the only province with mandatory government inspection at livestock auction markets, carried out by government appointed veterinarians. Therefore, Ontario was an ideal province for conducting this research. The 3 auction markets visited in this study were a convenience sample selected based on logistical considerations, in particular, selling cull cows on different days of the week (to allow for weekly visits), and their geographical location (to allow for daily commuting from the home of the primary observer).

Other nonauction locations throughout Ontario may also be used for the sale and collection of culled cows, but are not licensed or recorded in the provincial auction market reports used for reference in this study, and therefore are not represented in this project.

A sample size was difficult to estimate given the limited information published in this area. A preliminary unpublished pilot study, which observed just under 1,000 cows at an Ontario auction, conducted approximately 4 yr ago, yielded an average price of $\$ 0.49$ per $\mathrm{kg}$ and a standard deviation of $\$ 0.08$ [S. Emberson (University of Guelph, Guelph, Ontario, Canada), T. Duffield, and D. Haley, 2015]. In that study, the smallest difference between cows with abnormalities and normal cows was $\$ 0.01$ per kilogram. Using these data, it was estimated that approximately 1,400 cows would need to be sampled at an auction to find a difference in price of at least $\$ 0.01$ per kilogram with a power of $80 \%$ and with $95 \%$ confidence. Given that the pilot was conducted at only one auction a target sample size of 1,400 cows per auction was planned. This would have provided a total target sample size of 4,200 cows for the study. Based on this, observers aimed to collect data on 100 cows, per sale; however, reaching the minimum target sample was not possible at some auctions because of the small number of cows offered for sale on that day at that location. By referencing weekly auction market reports, 4 wk before the start date of data collection, we determined that the number of culled cows sold through the 3 auction markets represented approximately $40 \%$ of all culled cows sold at auction in Ontario during that time frame. Therefore, it is likely that this sample may be considered representative of Ontario culled cows sold at auction markets.

Observers arrived at the livestock auction market approximately $15 \mathrm{~min}$ before the scheduled start of the cull cow/slaughter cow portion of the sales. The 
date and time of the previous weeks' auction sale were reported on the auction market websites, which were used to determine the start time of the cull cow sales. Two observers stationed themselves within the stands intended for public viewing of the cattle, sitting no further than $10 \mathrm{~m}$ from the auction ring. Observers also sat in line with the door through which animals entered the ring to ensure a consistent viewing perspective of every animal across the different study sites.

Prior to sale, cattle were kept in group pens at the auction facilities. They may or may not have had access to food (dry hay) and water, depending on factors beyond our control (e.g., date of arrival at the facility, pen space available for holding). At the start of the sale, employees moved the cow to the sales ring where the cow was bid on. No information regarding the cow's origin, medical history, or transport duration was available for the research team to use.

For every culled dairy cow that entered the auction ring, the primary observer scored and recorded each cow's general physical condition by visually assessing and determining the hock injury score, BCS, gait score, and the presence or absence of a tail (see Table 1 for exact methods used). The secondary observers recorded the breed, BW shown on the auction ring scale, and the cow's sale price (\$/pound of BW) announced by the auctioneer. Data were then later converted to metric units $(\$ / \mathrm{kg})$. Government-appointed veterinarians, present at every sale, had the authority to condemn or prohibit the sale of any cow they felt could not be transported without undue suffering due to disease, injury, fatigue, or any other factor. Therefore, the cows observed in this study did not include the cows that were prohibited from sale. The exact number of cows condemned per sale was unknown to the researchers.

All variables used to score the general physical condition of the cows were adapted from proAction's Animal Care program (DFC-PLC, 2017), which uses a prescribed scoring system (Table 1). Observers had an average of $20 \mathrm{~s}$ of viewing time per cow, and were seated up to $10 \mathrm{~m}$ away from auction ring. Due to the difficulty of accurately distinguishing between 4 or 5 different categories, given the circumstances, each measure was categorized as either acceptable or unacceptable (Table 1). The use of these terms reflects terminology used in the proAction Animal Care standards manual (acceptable, needs corrective action, and monitor) and is based on whether the measures meet, or fail to meet, proAction standards. The primary observer was trained by a Holstein Canada Animal Care representative, and re-evaluated scoring resources every $3 \mathrm{wk}$ to retain intraobserver reliability. Secondary observers were brought to the auction market for one training session before the start of the data collection period. Observations were only made on dairy cows and heifers brought into the auction ring. Many breeds of dairy cows, were evaluated, including Holstein, Jersey, Brown Swiss, Ayrshire, and crosses. Beef cows, steers, bulls, and calves were excluded from this study. The observers were not blind to the hypotheses during data collection. Standardized data collection sheets were consistently used at every sale to record observations. Data were directly entered into an Excel spreadsheet (Microsoft Excel 2016, Microsoft Corp., Redmond, WA). The Excel spreadsheet was then imported into Statistical Analysis Software (SAS 9.4, SAS Institute Inc., Cary, $\mathrm{NC)}$ for statistical analysis.

\section{Statistical Analysis}

The frequencies of acceptable and unacceptable hock injury scores, BCS, gait scores, and tail scores were tabulated using the SAS procedure PROC FREQ (version 9.4, SAS Institute Inc.) with data sorted by location. To model the dependent variable, price, a general linear model was used with the procedure PROC MIXED (SAS 9.4). The fixed effects, or explanatory variables, included in the model were hock injury score, BCS, gait

Table 1. Variables used to determine the general condition of culled cows evaluated during sales at 3 auction markets, in Ontario, Canada, modified from, and in accordance with, Canadian proAction Animal Care standards (DFC-PLC, 2017)

\begin{tabular}{lll}
\hline Variable & Acceptable score & Unacceptable score \\
\hline Hock injury score $^{1}$ & $\begin{array}{l}\text { No or minor }(<1 \mathrm{~cm}) \text { swelling, no hair } \\
\text { loss, or balding area on hock }\end{array}$ & $\begin{array}{l}\text { Medium }(1-2.5 \mathrm{~cm}) \text { to major }(>2.5 \mathrm{~cm}) \text { swelling, broken skin (lesion) } \\
\text { or scab on bald area, or both }\end{array}$ \\
BCS $^{2}$ & BCS $>2$ & BCS $\leq 2$ \\
Gait score & $\begin{array}{l}\text { No limp present when observed for at } \\
\text { least 4 strides }\end{array}$ & $\begin{array}{l}\text { Limp is obvious (cow is favoring one or more limbs), walks with an } \\
\text { uneven, irregular jerky or awkward step, unable to track-up }\end{array}$ \\
Tail score & Full tail present & Tail removed above or at the switch \\
\hline
\end{tabular}

${ }^{1}$ Definitions for 4-point hock injury score provided by the 2017 Dairy Farmers of Canada, proAction Animal Care program.

${ }^{2}$ Definitions for 5-point BCS provided by Codes of Practice for the Care and Handling of Dairy Cattle (NFACC, 2009). 
score, tail score, BW, location, week, and breed. Except for location, 2-way interactions between all explanatory variables were tested as well as a quadratic term for BW. Location was treated as a blocking variable, a source of variation to be accounted for, but interactions with location were not thought to be meaningful due to the auction market wanting confidentiality to be maintained. Data were then converted from $\$$ /pounds to $\$ /$ kilogram. Because over 4,400 observations were made throughout the study, variables not significant at $P>0.001$ were removed from the model.

The assumptions of the ANOVA were assessed via residual analyses using PROC UNIVARIATE (SAS 9.4): Kolmogorov-Smirnov, Shapiro-Wilks, Cramér-von Mises, and Anderson-Darling. No tests were successful in normalizing the data. In addition, the residuals were plotted against the explanatory variables used in the model. Outliers were also removed from the data to attempt to normalize; however, this did not create normality and they were left in the data set. Therefore, no residual analysis was used. The least squares means were used to calculate the estimated price for each variable, and were plotted again each variable to determine how different scores affected the estimated sale price for the cow.

\section{RESULTS}

\section{General Description of Sample Numbers and Averages}

A total of 4,460 culled dairy cows were observed during 64 auction sales at 3 Ontario auction markets throughout the study period. Complete data were recorded for $95 \%$ of the cows assessed $(\mathrm{n}=4,235 / 4,460)$. Culled cows sold were predominantly Holstein (92.5\%) along with Jersey (3.8\%), Ayrshire (3\%), and Brown Swiss breeds $(<1 \%)$. Observations were made for 1,401 culled cows at location 1 (31.4\% of the sample), 1,290 culled cows at location $2(27.7 \%)$, and 1,769 culled cows at location $3(38 \%)$. For the price difference analysis, any culled cows assessed that did not have complete data were removed from the analysis $(\mathrm{n}=225)$. However, to determine the frequency of each variable measured for the general physical condition, all available data were used. Overall, data were recorded for 4,439 cows for a hock injury score, 4,457 cows for a BCS, 4,271 cows for a gait score, and 4,459 cows for a tail score.

The average sale price $(\$ / \mathrm{kg}$ of $\mathrm{BW})$ for culled cows was $\$ 1.94 / \mathrm{kg}$; however, the sale price varied by location. At location 1, culled cows sold for an average of $\$ 1.94$ / $\mathrm{kg}$ ranging from $\$ 0.24$ to $\$ 3.24 / \mathrm{kg}$. At location 2, culled cows sold for an average of $\$ 1.90 / \mathrm{kg}$ ranging from $\$ 0.53$ to $\$ 3.31 / \mathrm{kg}$. At location 3 , the average price $/ \mathrm{kg}$ was
$\$ 2.00$ ranging from $\$ 0.22$ to $\$ 0.81$. The average BW of the culled cows sampled was $640 \mathrm{~kg}$. Body weight also varied depending on location. Location 1 sold cows with an average BW of $642 \mathrm{~kg}$, ranging from 322 to $1,027 \mathrm{~kg}$. Location 2 sold cows with an average BW of $620 \mathrm{~kg}$, ranging from 218 to $993 \mathrm{~kg}$. At location 3 cows were sold with an average BW of $654 \mathrm{~kg}$, ranging from 302 to $1,102 \mathrm{~kg}$.

\section{General Condition of Culled Cows in Ontario}

The frequency of each measure scored as either acceptable or unacceptable (Table 1), according to proAction Animal Care standards (DFC-PLC, 2017), was calculated and plotted in Figure 1. For the 4,439 cows that had data recorded on hock injury score, $27.2 \%$ were scored as having an unacceptable hock injury score, meaning an injury was present on at least one leg with swelling greater than $1 \mathrm{~cm}$, a lesion, or both $(\mathrm{n}=1,209 / 4,439)$. For the 4,457 cows that had data recorded on BCS, $40.5 \%$ of culled cows scored had an unacceptable BCS of 2 or less, which is considered too thin $(\mathrm{n}=1,804 / 4,457)$. For the 4,271 cows that had data recorded on gait score, $72.7 \%$ of culled cows were scored as having an unacceptable gait, indicating that they had some abnormality in their stride that ranged from a severe limp to inability to track-up $(\mathrm{n}=$ $3,090 / 4,271)$. Last, for the 4,459 cows that had data recorded on tail score, $12.5 \%$ of culled cows had tails that were docked at or above the switch $(\mathrm{n}=550 / 4,459)$.

\section{Relationship to Price/Kilogram}

The final statistical model comparing the association between the general condition measures of the cows and price is presented in Table 2. Results showed a $\$ 0.20$ difference in the price paid $/ \mathrm{kg}$ for culled cows had a BCS $\leq 2$, compared with those that had a BCS $>2(P<$ $0.001 ; 95 \%$ CI: $0.18-0.21)$. There was a $\$ 0.05$ difference in price paid $/ \mathrm{kg}$ for culled cows that had an abnormal gait, compared with those that had a normal gait $(P<$ 0.001; 95\% CI: 0.035-0.066).

A significant interaction was observed between BCS and gait on price paid $/ \mathrm{kg}$, which is presented in Figure 2. If the cow had a normal gait, a $\$ 0.24$ difference in price paid $/ \mathrm{kg}$ was observed depending on whether the cow had a BCS $>2$ or a BCS $\leq 2(P<0.001 ; 95 \%$ CI: $0.20-0.26)$. Similarly, if the cow had an abnormal gait a $\$ 0.15$ difference was observed in the price paid $/ \mathrm{kg}$ depending on whether the cow had a BCS $>2$ or a BCS $\leq 2(P<0.001 ; 95 \%$ CI: $0.14-0.18)$. If BCS $>2$, there was a $\$ 0.09$ difference in price paid $/ \mathrm{kg}$ for cull cows with a normal gait compared with an abnormal gait $(P$ $<0.001$; 95\% CI: 0.068-0.101). 


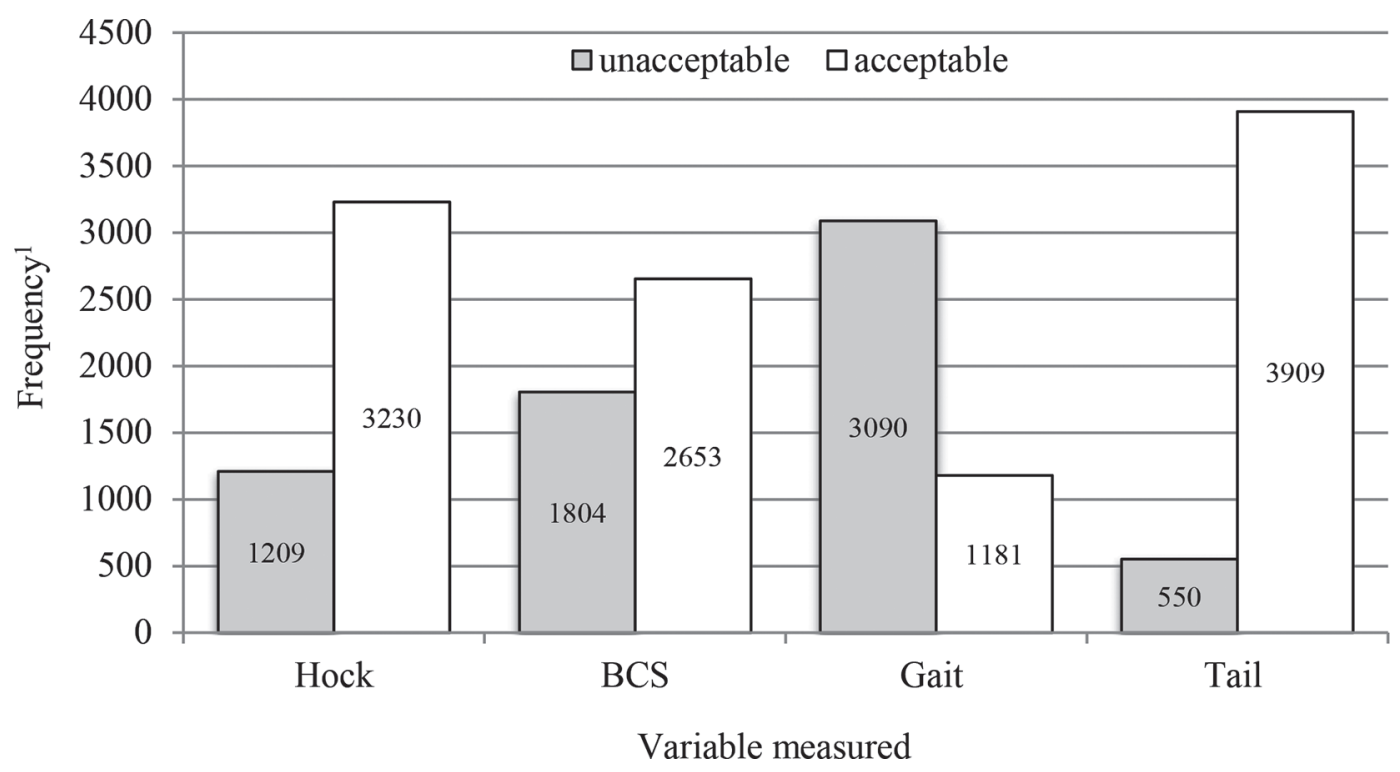

Figure 1. The frequency of acceptable and unacceptable scores given to culled dairy cows sold at 3 auction markets in Ontario, Canada, based on the 2017 Canadian proAction Animal Care guidelines (DFC-PLC, 2017) for animal-based measures. Acceptable hock = no injury present, or a hock with swelling less than $1 \mathrm{~cm}$, and balding only, no broken skin or scab; unacceptable hock = hock injury present with swelling greater than $1 \mathrm{~cm}$, broken skin/scab, or both; acceptable BCS $=$ BCS $>2$; unacceptable $\mathrm{BCS}=\mathrm{BCS} \leq 2$; acceptable gait $=$ no abnormalities observed in 4 consecutive strides; unacceptable gait = presence of limp or inability to track-up viewed during 4 strides; and acceptable tail = full tail; unacceptable tail $=$ a tail docked at or above the switch. Full data were available for 4,439 cows for hock scoring, 4,457 cows for BCS, 4,271 cows for gait scoring, and 4,459 cows for tail scoring.

Table 2. Final statistical model of the LSM for factors associated with dollars/kilogram for culled dairy cows sold at 3 Ontario auction markets, over $16 \mathrm{wk}$

\begin{tabular}{|c|c|c|c|c|c|}
\hline \multirow[b]{2}{*}{ Variable } & \multirow{2}{*}{$\begin{array}{l}\text { Estimated price }{ }^{1} \\
(\$ / \mathrm{kg})\end{array}$} & \multirow[b]{2}{*}{ SE } & \multicolumn{2}{|c|}{$95 \% \mathrm{CI}^{2}$} & \multirow[b]{2}{*}{$P$-value } \\
\hline & & & LCL & UCL & \\
\hline No sale & 0.00 & 0.00 & - & - & - \\
\hline \multicolumn{6}{|l|}{ Intercept } \\
\hline BCS & 1.48 & 0.093 & 1.28 & 1.65 & \\
\hline $\mathrm{BCS}>2$ & 2.01 & 0.011 & 1.98 & 2.03 & $<0.001$ \\
\hline $\mathrm{BCS} \leq 2$ & 1.81 & 0.013 & 1.79 & 1.83 & $<0.001$ \\
\hline \multicolumn{6}{|l|}{ Gait } \\
\hline Normal gait & 1.94 & 0.012 & 1.92 & 1.96 & $<0.001$ \\
\hline Abnormal gait & 1.89 & 0.011 & 1.87 & 1.92 & $<0.001$ \\
\hline \multicolumn{6}{|l|}{ Hock } \\
\hline No injury & 1.92 & 0.017 & 1.87 & 1.94 & $<0.001$ \\
\hline Injury & 1.90 & 0.017 & 1.87 & 1.94 & $<0.001$ \\
\hline \multicolumn{6}{|l|}{ Tail } \\
\hline Full tail & 1.92 & 0.016 & 1.87 & 1.94 & $<0.001$ \\
\hline Docked tail & 1.90 & 0.018 & 1.87 & 1.94 & $<0.001$ \\
\hline \multicolumn{6}{|l|}{ Location } \\
\hline Location 1 & 1.90 & 0.017 & 1.87 & 1.94 & $<0.001$ \\
\hline Location 2 & 1.87 & 0.018 & 1.85 & 1.92 & $<0.001$ \\
\hline Location 3 & 1.94 & 0.017 & 1.90 & 1.96 & $<0.001$ \\
\hline \multicolumn{6}{|l|}{ Breed } \\
\hline Holstein & 1.94 & 0.0044 & 1.94 & 1.96 & $<0.001$ \\
\hline Jersey & 1.70 & 0.17 & 1.65 & 1.74 & $<0.001$ \\
\hline Brown Swiss & 2.05 & 0.035 & 1.94 & 2.16 & $<0.001$ \\
\hline Other & 1.94 & 0.021 & 1.90 & 1.98 & $<0.001$ \\
\hline $\mathrm{BW}^{3}$ & 0.090 & 0.012 & 0.066 & 0.11 & $<0.001$ \\
\hline Week & 0.066 & 0.0029 & 0.062 & 0.073 & $<0.001$ \\
\hline
\end{tabular}

${ }^{1}$ Estimated price/kilogram $(\$ / \mathrm{kg}$ of $\mathrm{BW})$.

${ }^{2}$ Confidence interval for LSM, and lower (LCL) and upper (UCL) confidence limits.

${ }^{3} \mathrm{BW}$ in kilograms. 


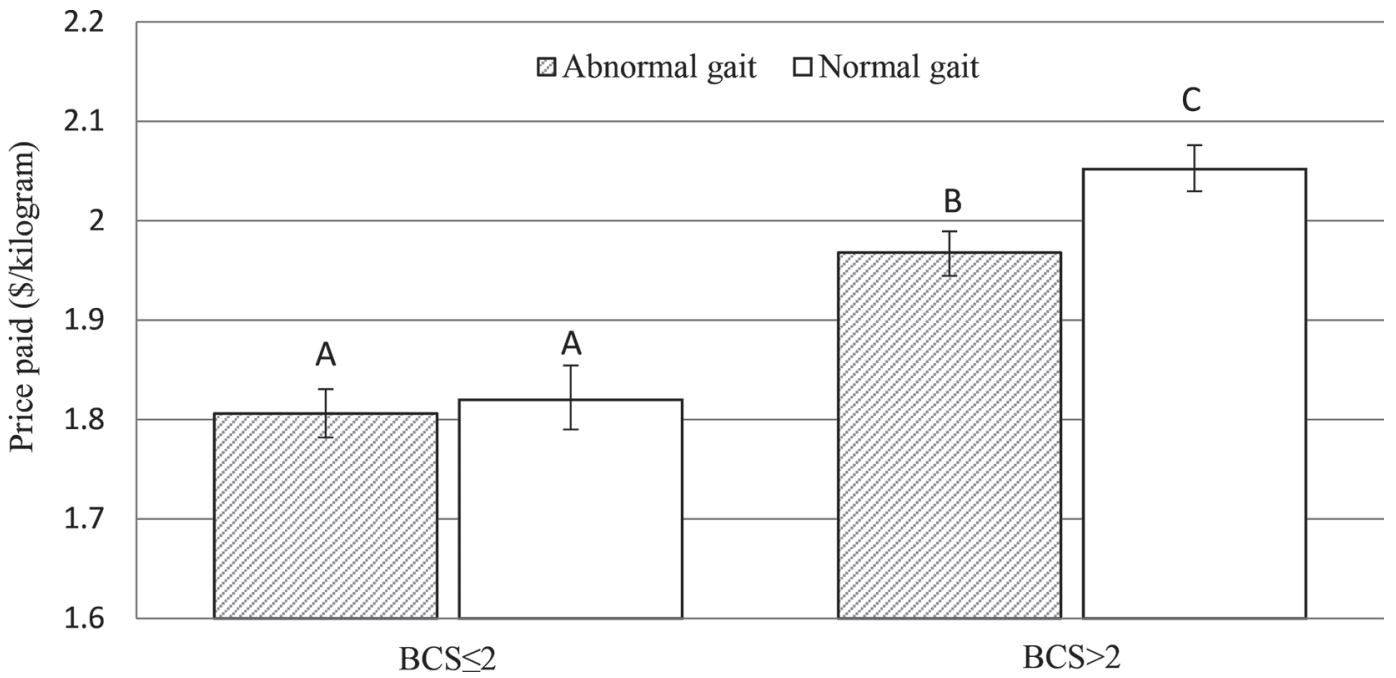

Figure 2. Estimated price paid $( \pm \mathrm{SE})$, in dollars/kilogram, for culled dairy cows sold at 3 Ontario auction markets, when the LSM was plotted against price to determine how score affected estimated sale price, and interaction between BCS and gait score variables was considered. Different letters $(\mathrm{A}-\mathrm{C})$ above the bar indicate a significant difference in estimated price paid per kilogram $(P<0.001)$.

No difference in the sale price $(\$ 0.009 / \mathrm{kg})$ was found for culled cows that had unacceptable hock injuries compared with those that had no hock injuries $(P=$ $0.23 ; 95 \%$ CI: $0.022-0.053)$. There was also no difference in the sale price $(\$ 0.007 / \mathrm{kg})$ for culled cows with docked tail compared with those with a full tail $(P=$ 0.4451; 95\% CI: 0.0011-0.024).

\section{DISCUSSION}

In Ontario, approximately 120,000 culled cows (beef and dairy) are marketed through licensed auction markets a year (Mike Draper, Ontario Ministry of Agriculture, Food, and Rural Affairs, Woodstock, ON, Canada, personal communications). Although the most common risk factors for culling are issues regarding the cow's milk production or fertility (Beaudeau et al., 1993; Bascom and Young, 1998; Chiumia et al., 2013), disease and injury can also contribute to a producer's decision to cull. A cow may be culled specifically because of that injury or disease, or because it results in a reduced performance by the cow (Dohoo and Martin, 1984; Grohn et al., 1997; Rajala-Schultz and Grohn, 1999a,b). If a cow is culled and transported to an auction market with a disease or injury present, it may not be able to withstand the stress of transport, and its welfare thus may subsequently be reduced (Canadian Food Inspection Agency, 2016).

Despite the growing interest in animal welfare, specifically surrounding livestock transport, this is the first study to document the general condition of culled dairy cows sold at licensed auction markets in Ontario. Due to the lack of previous research on this topic, it is unknown how frequently culled dairy cows are sent to auction markets in unacceptable conditions, as determined by recent industry guidelines for animal care. Having a benchmark of this frequency would provide insight for the industry, identify key areas of focus for improving livestock transport conditions throughout Canada, as well as protect animal welfare.

\section{General Condition of Culled Cows in Ontario}

The first objective of this study was to determine the general physical condition of culled cows sold at Ontario auction markets, and the frequency of culled cows with apparent physical problems sold at auction markets. The general physical condition of the culled cow was assessed in accordance with Dairy Farmers of Canada proAction Animal Care standards (DFC-PLC, 2017). Since their implementation, these standards are the new national standard in assessing animal care and welfare. The general condition of several of the culled cows sold at auction sampled in this study did not meet proAction's industry standards. Because these standards were only implemented in September 2017, after the data collection period had been completed, it may be of value to repeat this study in future to assess whether the industry has made progress.

Regarding hock injury scores, $27 \%$ of culled cows observed had a hock injury present on at least one leg with medium to major swelling, a lesion present, or both. A recent study (Zaffino Heyerhoff et al., 2014), which is the largest of its kind in Canada, found that $47 \%$ of 2713 cows, measured across 90 freestall farms, had at least one hock injury present, when using the 
same scoring criteria as the present study. Similarly, a study completed by Nash et al. (2016), found that $52 \%$ of the 3868 cows measured, across 100 tiestall farms in Quebec and Ontario, had a hock injury present, when using the same scoring criteria as the present study. Comparing these finding to the results in the current study shows that the frequency of unacceptable hock scores was lower at the auction market than what has previously been reported on farm. Hock injuries have been widely accepted as a welfare concern for dairy cattle by the scientific community and by expert opinion (Whay et al., 2003). The results found in this study may indicate that progress is being made in identifying and preventing hock injuries in dairy cattle, as it is a highly prevalent injury within the industry and has become an area of focus in the proAction Animal Care standards. Alternatively, methodological differences in the current study compared with previous studies cited (study population, study period, reduced time to assess injuries, and viewing animals from a greater distance), may have yielded a more conservative prevalence of injuries at the auction markets.

The results of the BCS of culled cows sampled in this study illustrated that $40 \%$ of culled cows had a BCS $\leq 2$, which is considered too thin according to proAction Animal Care Standards (DFC-PLC, 2017). Roche et al. (2009) reported that cows that calve with lower body condition were likely to have lower milk production, had reduced fertility with a longer postpartum anestrus interval, and were more likely to be categorized as being at risk for reduced welfare. These results suggest that low BCS is related to common risk factors for culling such as milk production and fertility problems, potentially explaining the high prevalence of low body condition (Bascom and Young, 1998). Additionally, in a study completed by Norring et al. (2014), with data collected on 70 milking cows regarding feeding behavior and gait scoring, results indicated that cows had reduced feed intake and reduced allocated time to feeding at or before visible change in gait. It is likely, if feed intake decreases, that body condition will also decrease to compensate, potentially resulting in low BCS. Hence, as the many reasons leading to culling may contribute to dairy cows losing weight, it was not unexpected that a high proportion of culled cows sold at auction markets had low BCS. Further research is needed to examine the possible relations between animal welfare and low BCS, specifically how culled dairy cows with low BCS respond to transport and being sold at auction.

In this sample of culled cows, $72 \%$ had some abnormality in their stride, which ranged from an inability to track-up to a severe limp. Previous research conducted in Ontario, Canada, which assessed 40 freestall barns, found that the average prevalence of on-farm lameness was from 20 to $30 \%$ of the milking herd, and was as high as 69\% (Solano et al., 2015). Therefore, when comparing previous findings of abnormal gait on dairies to the findings in this study, our results are not unexpected. Additionally, previous research has indicated that lameness can affect the risk of culling. Booth et al. (2004) reported that lameness increased a cow's risk for being culled, depending on DIM at diagnosis. Barkema et al. (1994) found that lameness can have a negative effect on reproductive performance, one of the most common risk factors for culling dairy cows. The results from these previous studies may help to explain why over two-thirds of the cows sampled in the current study had an abnormal gait. Future research is needed to assess how abnormal gait and lameness may affect the welfare of culled cows during transport and how the conditions of transport influences lameness severity.

Finally, $12 \%$ of culled cows sampled had their tails docked at or above the switch. The practice of tail docking in dairy herds remains prevalent in North America despite substantial research that shows no benefit to the practice (Matthews et al., 1995; Tucker et al., 2001). The National Animal Health Monitoring System (2014) reported $49.5 \%$ of dairy cow operations in the United States had at least one or more cows with a docked tail. With the implementation of proAction Animal Care standards in September 2017 in Canada, performing tail docking on dairy farms is now prohibited unless deemed medically necessary by a veterinarian. In preparation for adhering to these new standards, farmers may feel pressured to cull cows that already have docked tails to improve their chance of scoring well in their initial proAction Animal Care assessment.

\section{Relationship to Price/Kilogram}

The second objective of this study was to examine whether an association was present between the general physical condition of culled cows sold at auction and sale price. We found that culled cows with BCS $\leq 2$ sold for less compared with cows with BCS $>2$. Considering that the average BW for culled cows with BCS $\leq 2$ sampled in this study was $584 \mathrm{~kg}$, and applying the difference in price to this lower average $\mathrm{BW}$, the overall loss was approximately $\$ 117$ thin cow. Although, buyers may look for leaner animals, as their meat will typically be used for food products such as lean/extra-lean ground beef or hamburger, this difference in price may largely be influenced by extremely thin cows (BCS 1), as the buyers may be hesitant to buy a cow that looks emaciated.

Culled cows that had an abnormal gait sold for less. This difference in price approximated to a loss of $\$ 32$ / 
cow. As mentioned previously, abnormal gait, specifically lameness, is related to multiple diseases within the dairy industry, and therefore may be perceived negatively by the buyers, because lame cows could be at risk of having other less obvious problems. Further, purchased culled cows are transported after the sale to abattoir, and buyers may be concerned about the risk of potential losses from transporting a lame cow who has a greater likelihood of becoming recumbent during transport, leading to euthanasia or condemnation. More research is needed following culled cows through the entire food system from farm, through auction, to abattoir to assess fitness for transport and how it may be affected by different transit conditions.

A relationship was also observed between BCS, gait, and the effect on price (Figure 2). Culled cows with a BCS $>2$ and a normal gait sold for more compared with culled cows with a BCS $\leq 2$ and a normal gait. Similarly, culled cows with an abnormal gait and a BCS $>2$ sold for more compared with culled cows that had an abnormal gait and a BCS $\leq 2$. These results indicate that a difference in BCS has a more profound effect on price compared with a difference in gait score. If a cow was considered too thin, differences in the sale price depending on gait score were minor. However, if a cow was well conditioned (BCS $>2$ ) the differences in the sale price due to differences in gait score were larger. According to the Codes of Practice for the Care and Handling of Dairy Cattle (National Farm Animal Care Council, 2009), neither too thin, or lame cows are fit for transport, and should be treated on farm. However, in this case, the concern for abnormal gait seems to be more prominent in well-conditioned cows, compared with thin cows. Future research to assess how lameness and BCS affect buyers' decisions is needed to further encourage producers to refrain from shipping thin or lame cattle.

No difference was observed in the sale price between culled cows that had acceptable versus unacceptable hock injury scores (see Table 1), or for culled cows with a full tail compared with those that had a docked tail. These results suggest that there is no financial penalty for producers sending culled dairy cows to auction with hock injuries or docked tails. Reasons for the lack of association between these aspects of the cow's condition and the sale price are unknown; however, it may be that these measures are not something that concerns buyers when assessing the value of the cow. Cows with hock injuries are not necessarily lame, thus there may be less risk to the buyer. Additionally, little research has been done to indicate how hock injuries are associated with other health conditions. As such, this may contribute to a general lack of concern regarding hock lesions by cull cow purchasers. Similarly, a full tail or a docked tail has minimal effect on the overall health or condition of the cow when being viewed at auction; therefore, it is unlikely to affect the buyer's decisions. Docked tails are also not assessed at abattoirs, and there is no consequence to buying a cow with a docked tail for slaughter.

This study is limited by the fact that results can only be interpreted for the specific time frame and locations used during the study period. The 3 locations visited in this study sell a large proportion of culled cows sold in Ontario (see methods), and therefore, is likely representative of culled dairy cows sold in Ontario. Prices at which these cows are sold can vary at different times due to many factors, such as consumer demand, the US dollar relative to the Canadian dollar, and economic market. Because of the influence of these factors, we cannot make inferences about seasonal trends at auction markets and therefore the data may not be predictive of what one could expect to see next year, or a decade from now.

\section{CONCLUSIONS}

Culling is an important aspect of the dairy industry, and culled cows are constantly being bought and sold throughout Canada. This study provides the first benchmark of the condition of culled dairy cows sold at Ontario auction markets. Results showed that in many cases culled cows in less than optimal condition are transported to auction markets in Ontario and sold. Despite regulations in Canada that describe when an animal can and cannot be transported, results from this study show that culled cows are sold at auction markets in conditions which do not meet industry standards and Ontario transport regulations. The main issues identified with culled cows in this study were low BCS (too thin) and abnormal gait. Both translated into a lower sale price for the animal compared with those that were in good condition, which reduces potential profits for the dairy producer. Further research is required to determine ways to prevent the transport and sale of cows in poor general condition to protect their welfare and also to improve revenue for the producer. Future research is needed to assess fitness for transport for culled dairy cows and whether this may be affected or limited by their general physical condition.

\section{ACKNOWLEDGMENTS}

This research was funded by the OMAFRA-University of Guelph partnership through the Highly Qualified Personnel graduate scholarship program, and by the Dairy Farmers of Ontario (Mississauga, ON, Canada) program initiative. The authors also thank those re- 
search experts and auction market managers who assisted in the completion of this project. An additional thank-you to student volunteers Amanda Armstrong, Taylor Braden, Angela Graham, and Emma Morrison (University of Guelph, Guelph, ON, Canada) for assisting in data collection. Without this help the completion of this research project would not have been possible.

\section{REFERENCES}

Barkema, H. W., J. D. Westrik, K. A. S. Van Keulen, Y. H. Schukken, and A. Brand. 1994. The effects of lameness on reproductive performance, milk production and culling in Dutch dairy farms. Prev. Vet. Med. 4:249-259.

Bascom, S. S., and A. J. Young. 1998. A summary of the reasons why farmers cull cows. J. Dairy Sci. 81:2299-2305.

Beaudeau, F., A. Henken, C. Fourichon, K. Frankena, and H. Seegers. 1993. Associations between health disorders and culling of dairy cows: A review. Livest. Prod. Sci. 35:213-236.

Booth, C. J., L. D. Warnick, Y. T. Grohn, D. O. Maizon, C. L. Guard, and D. Janssen. 2004. Effect of lameness on culling in dairy cows. J. Dairy Sci. 87:4115-4122.

Canadian Food Inspection Agency. 2016. Health of animals regulations part XII: Transportation of animals. Accessed Oct. 20, 2017. http: //laws-lois.justice.gc.ca/eng/regulations/C.R.C.,_c._296/.

Chiumia, D., M. G. Chagunda, A. I. Macrae, and D. J. Roberts. 2013. Predisposing factors for involuntary culling in Holstein-Friesian dairy cows. J. Dairy Res. 80:45-50.

De Vries, A., J. D. Olson, and P. J. Pinedo. 2010. Reproductive risk factors for culling and productive life in large dairy herds in the eastern United States between 2001 and 2006. J. Dairy Sci. 93:613-623.

DFC-PLC (Dairy Farmers of Canada-Producteurs Laitier du Canada). 2017. proAction Reference Manual \& Workbook integrated for Food Safety, Animal Care, and Traceability modules. Dairy Farmers of Canada, Ottawa, Ontario, Canada.

Dohoo, I. R., and S. W. Martin. 1984. Disease, production and culling in Holstein-Friesian Cows. IV. Effects of disease on production. Prev. Vet. Med. 2:755-770.

Fetrow, J., K. V. Nordlund, and H. D. Norman. 2006. Invited review: Culling: nomenclature, definitions and recommendations. J. Dairy Sci. 89:1896-1905.

Grohn, Y. T., S. W. Eicker, V. Ducrocq, and J. A. Hertl. 1998. Effect of diseases on the culling of Holstein dairy cows in New York state. J. Dairy Sci. 81:966-978.

Hadley, G. L., C. A. Wolf, and S. B. Harsh. 2006. Dairy cattle culling patterns, explanations and implications. J. Dairy Sci. 89:22862296.

Langford, F. M., and A. W. Scott. 2012. Culled early or culled late: Economic decision and risks to welfare in dairy cows. Anim. Welf. 21:41-55.

Martin, S. W., S. A. Aziz, W. C. D. Sandals, and R. A. Curtis. 1982. The association between clinical disease, production and culling of Holstein Friesian cows. Can. J. Anim. Sci. 62:633-640.
Matthews, L. R., A. Phipps, G. A. Verkerk, D. Hart, J. N. Crockford, J. F. Carragher, and R. G. Harcourt. 1995. The effects of tail docking and trimming on milker comfort and dairy cattle health, welfare and production. Pages 1-25 in Animal Behaviour and Welfare Research Centre Rep. Minist. Agric. Forestry, Wellington, New Zealand.

Milian-Suazo, F., H. N. Erb, and R. D. Smith. 1989. Risk factors for reason-specific culling of dairy cows. Prev. Vet. Med. 7:19-29.

Nash, C. G. R., D. F. Kelton, T. J. DeVries, E. Vasseur, J. Coe, J. C. Zaffino Heyerhoff, V. Bouffard, D. Pellerin, J. Rushen, A. M. de Passillé, and D. B. Haley. 2016. Prevalence of and risk factors for hock and knee injuries on dairy cows in tiestall housing in Canada. J. Dairy Sci. 99:6494-6506.

NFAHW (National Farm Animal Health and Welfare Council). 2017. The management of culled dairy cows in Canada. Accessed Oct. 30, 2017. http://www.ahwcouncil.ca/pdfs/cullcow/NFAHW\%20 Council_Recommendation_The\%20Management\%20of\%20Cull \%20Dairy\%20Cows\%20in\%20Canada_2017.pdf.

National Farm Animal Care Council. 2009. Codes of practice for the care and handling of dairy cattle. 1st ed. Accessed Oct. 15, 2017. http://www.nfacc.ca/codes-of-practice/dairy-cattle.

National Animal Health Monitoring System. 2014. Health and management practices on U.S. dairy operations, 2014. Accessed Apr. 5, 2017. https://www.aphis.usda.gov/animal_health/nahms/dairy/ downloads/dairy14/Dairy14_dr_PartIII.pdf.

Norring, M., J. Haggman, H. Simojoki, P. Tamminen, C. Winckler, and M. Pastell. 2014. Short communication: Lameness impairs feeding behaviour of dairy cows. J. Dairy Sci. 97:4317-4321.

Rajala-Schultz, P. J., and Y. T. Grohn. 1999a. Culling of dairy cows. Part I. Effects of diseases on culling in Finnish Ayrshire cows. Prev. Vet. Med. 41:195-208.

Rajala-Schultz, P. J., and Y. T. Grohn. 1999b. Culling of dairy cows. Part II. Effects of diseases and reproductive performance on culling in Finnish Ayrshire cows. Prev. Vet. Med. 41:279-294.

Roche, J. R., N. C. Friggens, J. K. Kay, M. W. Fisher, K. J. Stafford, and D. P. Berry. 2009. Invited review: Body condition score and its association with dairy cow productivity, health, and welfare. J. Dairy Sci. 92:5769-5801.

Solano, L., H. W. Barkema, E. A. Pajor, S. Mason, S. J. LeBlanc, J. C. Zaffino Heyerhoff, C. G. R. Nash, D. B. Haley, E. Vasseeur, D. Pellerin, J. Rushen, A. M. de Passille, and K. Orsel. 2015. Prevalence of lameness and associated risk factors in Canadian HolsteinFriesian cows housed in freestall barns. J. Dairy Sci. 98:6978-6991.

Tucker, C. B., D. Fraser, and D. M. Weary. 2001. Tail docking dairy cattle: Effects on cow cleanliness and udder health. J. Dairy Sci. 84:84-87.

Whay, H. R., D. C. J. Main, L. E. Green, and A. J. F. Webster. 2003. Animal-based measures for the assessment of welfare state of dairy cattle, pigs and laying hens: Consensus of expert opinion. Anim. Welf. 12:205-217.

Zaffino Heyerhoff, J. C., S. J. LeBlanc, T. J. Devries, C. G. R. Nash, J. Gibbons, K. Orsel, H. W. Barkema, L. Solano, J. Rushen, A. M. de Passille, and D. B. Haley. 2014. Prevalence of and factors associated with hock, knee, and neck injuries on dairy cows in freestall housing in Canada. J. Dairy Sci. 97:173-184. 